The Section on the Gall Bladder is written in conjunction with Dr. Rowden. This is followed by Appendices. These have no direct reference to the Alimentary Canal, but deal with various problems of the working radiologist-the organization and equipment of an X-ray department, the radiation risks of the radiologist, the legal ownership of $\mathrm{X}$-ray films, and so on.

Much of the work of these appendices has been done by the author himself. This, together with the discussion of screening technique, the description of the physiological mechanism of swallowing, and of the anatomical positions of the abdominal viscera as well as numerous notes throughout the book, represent the personal observations of an acute observer.

Full details of the latest methods are not given, and no attempt is made to do so. A thorough understanding of the contents of the book, however, will give a very firm foundation on which to base the manipulative skill necessary for barium--meal examinations, and one which is also required in the newer methods.

The printing and illustrations are excellent. The writing throughout is in the most pleasant style, and this makes it the most readable book on radiology in the English language. To beginners in radiology, the book is essential. There is no alternative.

\section{DISEASES OF THE NEWBORN.}

By Abraham Tow, M.D. Oxford Medical Publications. 1937. Price 27/6.

In reviewing a book on this subject one immediately thinks of the famous volume by von Reuss and translated into English by J. D. Rolleston. The volume by von Reuss is so detailed in its descriptions, so fully and magnificently illustrated (often in colour) and supplied with such an extensive bibliography, that any less full treatise of the subject must suffer in comparison.

It is for these reasons perhaps that we cannot write so enthusiastically of Prof. Abraham Tow's treatise as we would desire. Nevertheless, the book will have a wide range of usefulness. It will be of great value to the medical student and to the general practitioner for it covers the field of the subject sufficiently thoroughly for their purpose and with a detail that is not the rule in the general run of text-books on pædiatrics. It is, however, to be regretted that a paper with a higher degree of polish was not used as this has militated against the reproduction of the illustrations to such an extent that in not a few instances we are doubtful if they will convey much information to the non-expert.

\section{CHRONIC STREPTOCOCCAL INFECTION AS A DISEASE.}

By J. D. Hindley-Smith, M.A., M.R.C.S., L.R.C.P. London 1937. H. K. Lewis \& Co., Ltd., pp. $\mathbf{x}+$ 44. Crown 8vo. Price $3 / 6$ net.

The keynote of this attractive little book is to be found in the short preface of only five lines, which at once arrests attention and attracts the reader. The practical viewpoint of the author is here apparent, and in the succeeding pages we see his determination to study the disease of which he writes not by compiling a sterile classification of signs and symptoms, such as is found in the majority of text-books, but in relation to the fundamental principles of general pathology, of which he has evidently a true and vital conception.

It has often been said, and not without justice, that clinical impressions, apart from hard and fast experimental evidence, are dangerous and frequently misleading. Nevertheless their value cannot be gainsaid, nor can it be denied that some of the most useful and practical advances in medical thought have emanated from the intuitive mind of the clinician rather than from the stereotyped machinery of the laboratory. Dr. Hindley-Smith is evidently one of those thinkers who have the happy knack of combining the lessons of clinical observation with those of pathology, and his short monograph on the ætiology and external manifestations of chronic streptococcal toxæmia appeals to us as both suggestive and convincing. It makes no claim to be more than a condensed and introductory statement of his views, but it is so clearly written and with such freedom from undue dogmatism that we commend it strongly to our readers.

This book creates a desire for more of the same calibre, and we sincerely hope that it is but the preliminary to a larger and more detailed work by the author on this most important subject. 